\title{
THE INTERSECTION OF BIOPHILIA AND ENGINEERING IN CREATING SUSTAINABLE, HEALTHY AND STRUCTURALLY SOUND BUILT ENVIRONMENTS
}

\author{
ELAINE AYE, DANIEL HACKETT \& CHIARA POZZUOLI \\ RWDI, Guelph, Canada
}

\begin{abstract}
As horizons in the urban world are increasingly diminished by the encroachment of skyscrapers and tall structures, humanity is lifting away from the natural environment. For generations, cities have been designed in ways that degrade the environment and alienate inhabitants from nature. With the densification of cities, building vertically is an obvious and sustainable choice - yet there are no trees, gardens or green spaces in the sky. A growing trend is for architects and engineers to create new ecosystems within urban high-rise environments, incorporating the concepts of biophilia - the inherent human instinct to connect to nature and the natural world. Biophilic design, by extension, weaves natural materials, natural light, vegetation, nature views and other experiences of the natural world into the built environment. This paper examines this overlooked aspect of our built environments, and the synergy between effective engineering and biophilic design. As engineers, we consult on the interactions of a building, its surrounding environment, and the human experience, taking a holistic approach while asking critical questions: Is it structurally safe? Is it sustainable? Does it contribute to occupant health and comfort at every level, while protecting those on the street below? We vet structural integrity and enhance occupant comfort as it relates to wind and thermal impact. For instance, if trees are added to 40-story-tall balconies, or an exterior green wall is integrated with cladding, it is vital to test wind loads to ensure stability and safety. While trees and greenery can reduce exposure to sun, block unwanted winds, and filter air, thereby increasing occupant well-being, they can also pose unique risks that may require creative engineering. The future of building is deepening in complexity, but with biophilic design and state-of-the-art engineering, we can create a utopian standard that binds modernization with the natural world.
\end{abstract}

Keywords: biophilia, biophilic design, wind engineering, consulting, consultant, wind speed, wind tunnel, CFD, health and well-being.

\section{INTRODUCTION}

Horizons in the urban world are increasingly being diminished by the encroachment of skyscrapers and tall structures, a phenomenon which in turn is separating humanity from the natural environment. This separation affects people in different ways, but frequently can lead to problems ranging from a general malaise and lack of well-being to serious physical, physiological and psychological distress.

One frequent manifestation of these problems is work-related stress, which results in poor worker productivity and missed time due to illness. However, studies over the years have confirmed that people who are exposed to and spend time in more natural settings observe general health benefits, have better cognitive functionality and performance, experience better psychological and physiological health and well-being.

This is where the design community has an opportunity to proactively counter the distressing effects of the urban habitat on the people who live there.

\section{CAN'T WE DO BETTER?}

For generations, cities have been designed in ways that degrade the environment and alienate people living in the city from nature. Based on research that shows "the presence of trees and 
grass may be one of the key components of vital neighborhood spaces" [1], the design community has endeavoured to reverse this trend by incorporating biophilic elements new projects. However, with the densification of cities, building vertically has been an obvious and sustainable choice - yet there typically are no trees, gardens or green spaces in the sky.

The good news is that the architectural, engineering, and construction (AEC) community today has the tools and the ability to make a difference in the urban environment by reintroducing elements of nature into building design.

To this end, there is a growing trend among architects and engineers to incorporate the concepts of biophilia into their designs to create new ecosystems within urban high-rise environments.

The sociologist Eric Fromm introduced the term biophilia in his 1973 book The Anatomy of Human Destructiveness, describing it as "the passionate love of life and all that is alive". The American biologist Edward O. Wilson later popularized the term in his 1984 book Biophilia, which proposed a genetic basis for the tendency of humans "to focus on and to affiliate with nature and other life forms" [2].

Biophilic design endeavors to fulfill this inherent human instinct to connect to nature and the natural world by weaving into the built environment natural materials, natural light, vegetation, nature views and other experiences of the natural world.

This presentation examines this overlooked aspect of our built environments, and the synergy between effective engineering and biophilic design. The paper begins with a discussion of what biophilic design is and some of the reasons for considering this approach when designing a building. This is followed by an explanation of how biophilic concepts are executed and examples of the engineering support they may require. Finally, several examples are presented demonstrating the AEC community's accomplishments in biophilic projects.

\section{IT'S A PRESSING PROBLEM}

The world is becoming more urban every day. Industrialized nations saw their populations shift toward cities in the 19th and 20th centuries. By the 1920s, the number of people in the United States living in cities already had grown to surpass the number living in rural areas, and urbanization continued, albeit at a different pace, around the world [3]. The United Nations (U.N.) reports that in 2009 , now nearly a decade ago, the world's population first became more urban than rural. And this trend toward urbanization is only expected to continue: The U.N. estimates that the world urban population will increase by more than 80 percent by 2050, which means a growing number of people will be subjected to the stresses of urban living [4]. This affects corporate well-being as well as the health and wellness of individual people.

As previously noted, the cause of poor productivity often can be traced back to stress. Although it is difficult to attribute exact numbers to the problem, the corporate world loses billions of dollars each year on lost productivity due to stress-related illnesses. It is therefore important for those that design, operate, and manage buildings or own companies that employ human resources to consider all the potential ways to create better environments for those who inhabit the buildings.

There always have been pockets of sensitivity to the advantages of balancing nature and the built environment. But only since the latter part of the 20th century has the importance of sustainability in the built environment - as well as in many other aspects of modern life come to be more generally acknowledged and better understood. Out of a growing global awareness on this front, numerous rating systems, such as LEED, have been developed around the world to measure the sustainability of structures and to quantify their performance. 
However, these early efforts have been primarily focused on the relationship between the constructed projects and the environment. Primary goals have included increasing energy efficiency and reducing the use of natural resources, which also encompasses waste reduction.

More recent guidelines are now looking at the challenges posed by the built environment from a somewhat different perspective, evaluating how people are faring in these structures. The WELL Building Standard is one example of this enlightened approach. Going beyond the performance of the building and its systems, the WELL program "fosters a holistic formula for better health and wellness outcomes, leading to improvements in things like employee productivity, engagement and retention" [5]. Instead of simply promoting efficient structures, such an approach seeks to promote and support health and well-being in the daily lives of people who use the building. And taking a biophilic approach to achieve this is proving to be both effective and challenging.

The effects of biophilic elements in residential settings also have been researched and show real benefits. For example, Kuo and Sullivan [6] studied a Chicago housing project and found that buildings with more greenery had less assault, homicides, vehicle thefts, burglary and arson. Buildings with the most greenery and green views had 48 percent fewer property crimes and 56 percent fewer violent crimes than buildings with the least greenery.

Fortunately, many people have put a great deal of thought into how building designers can bring human exposure to nature back into the urban environment. One very useful description of how to think about this type of the solutions can be found in 14 Patterns of Biophilic Design [7]. Authored by three of the leading authorities in this field - Bill Browning, Catherine Ryan, and Joseph Clancy - this book breaks down biophilic design into three categories of nature-design relationships with a total of 14 subcategories, or patterns. By developing an understanding of these categories and subcategories, designers can develop and incorporate strategies for including biophilic elements in their designs.

\section{NATURE-DESIGN RELATIONSHIPS}

4.1 Nature in space includes seven biophilic design patterns

- Visual connection with nature

- Non-visual connection with nature

- Non-rhythmic sensory stimuli

- Thermal and airflow variability

- Presence of water

- Dynamic and diffuse light

- Connection with natural systems

Implementing any of these design patterns provides the building occupant with an awareness of the naturally occurring processes in nature, especially the seasonal and temporal changes characteristic of a healthy ecosystem.

4.2 Natural analogues include three patterns of biophilic design

- Biomorphic forms and patterns

- Material connection with nature

- Complexity and order 
Tapping into the organic non-living and indirect feelings or thoughts associated with nature, these elements provide rich sensory-filled experiences that can be mimicked in a spatial hierarchy.

\subsection{Nature of the space encompasses four biophilic design patterns}

- Prospect

- Refuge

- Mystery

- $\quad$ Risk/Peril

Addressing the spatial configurations found in nature, this type of feature - a high-level balcony or an elevator that whisks you to a rooftop overlooking the city, for example presents a threat or a thrill that has the safeguard of a known security.

With this categorization in hand as a guide, applying biophilic design becomes a matter of making selections, just as one would proceed in any other type of design. In this case, however, the calculus goes deeper than choices based on strength, economics, and appearance, for biophilic materials typically bring additional benefits - namely, improvements in human health and well-being - to the end product. However, the decision to use biophilic materials and methods also may require more and different types of engineering support than projects using only traditional materials and concepts. The next section covers some examples that demonstrate both the additional benefits and the additional challenges that come with a biophilic approach.

\section{HOW TO MAKE IT WORK}

A structure requires both a concept and the execution of that concept. The architect typically develops the concept and consults with the engineer on the interactions of the building with its surrounding environment, including the human experience. Taking a holistic approach, the engineer asks numerous critical questions: Is the building structurally safe? Is it sustainable? Does it contribute to occupant health and comfort at every level, while protecting those on the street below? The consulting engineer often is charged with both vetting structural integrity and enhancing occupant comfort as it relates to wind and thermal impact.

This also can be an opportunity for the consulting engineer to advocate for a biophilic approach. Because the consulting engineer's team typically brings great breadth and depth of experience and understanding to the project, these individuals are ideally suited to help optimize the human experience through an enhanced climate-responsive design. This includes encouraging a connection to nature through biophilic design - weaving elements and experiences of the natural world, such as plants, water features, and natural ventilation, into the built environment - and tempering the physical environment to make it usable yearround.

In supporting the architect on projects intended to incorporate biophilic design, the consulting engineer may be asked to evaluate a variety of environmental effects: the potential for wind-generated noise or structural loads due to patterns used in the building façade, for example, or the extent to which nearby areas will receive less direct sunlight (and more shade) throughout the course of a year, and so on. Frequently, however, engineers are engaged to work with the architect and the landscape architect to develop their landscaping either for the ground level spaces around the new development or the podium and terrace areas in a way that improves the environment for their occupants and users of these spaces.

In so doing, three key terms describe the process: technical, holistic, and collaborative. 


\subsection{Technical}

Biophilic design is more than just a collection of nice ideas. There is science behind all the concepts. This allows the engineer to assess and quantify their effects as part of the design process.

\subsection{Holistic}

Many of the objectives of biophilic design can conflict with each other. There is a need to take all aspects into consideration to find the optimum design. Although one might think that looking at any one of these environmental or human factors individually would be sufficient, in reality they all interact. And because of that, when trying to design something like a landscape for open spaces, all the different factors must be taken into account. Otherwise, attempts to optimize the space for thermal comfort and shading may be implemented at the expense of some other parameter.

\subsection{Collaborative}

The most successful designs are those where the technical aspects of design are considered early in the process. This is particularly true in biophilic design, where technical consultants and designers - the architects and landscape architects - must work together. The fact is, there is a reason engineers are not hired to design buildings: the world would be filled with a bunch of very similar square boxes. But through collaboration, the architect can design a building with visual appeal and an underlying philosophy while the engineer ensures that the science behind the structure and its accompanying systems is sound. This is how we achieve designs that are both appealing visually and appealing environmentally.

\section{STARTING AT GROUND LEVEL}

Natural materials - shrubs, trees, and other plants - have always been used to landscape around buildings. Taking an engineered approach in this area helps ensure that landscaping is not treated as an afterthought, just to make things look nice, but rather that the landscaping is used in a way that makes things better. When landscaping is designed to control wind, temperature, sunlight, noise, and air quality, the end result is a space that looks good and feels good, too.

\subsection{Wind mitigation}

One of the more obvious applications for landscaping is in addressing the aerodynamic problems of wind comfort and wind safety. When a building is constructed in the wind, which is to say anywhere, the wind will flow around it. If the building is very big or very tall, it can cause some fairly high wind speeds around the base of the building to the point where it is very much a safety issue. There have been cases, thankfully rare, where people have been injured or killed because of high wind speeds generated by buildings. More often, however, spaces just do not feel comfortable. And if spaces are not comfortable because its windy, people are not going to want to spend time there. Any developer who is planning to include retail space - cafes, restaurants, and bars, for example - at the ground level of a new development is going to want to know that people can use that area, that they will feel comfortable sitting outside, having a drink, eating their lunch, or reading a newspaper. They know that if people are not going to use that area, that it can greatly impact the profitability of their investment. 
The engineer first can assess what the wind is going to do around any building. This often involves testing instrumented scale models of the building and surrounding area in a wind tunnel. Similar analysis can be done in a computational setting using computational fluid dynamics (CFD). The idea is to discover what is happening with the wind around a building in any given setting. Having done that, using either or both of those methods, the engineer then can apply a set of criteria to those windspeed results to determine how comfortable or safe the area is going to be based on what the wind speed is and how often that wind speed occurs. If it is determined that the area will be uncomfortable or unsafe, some type of mitigation can be proposed. And in almost every case, that involves landscaping trees and shrubs, because these natural materials frequently are the best kind of wind mitigation.

Trees especially have a lot of properties that make them very useful for breaking up and dispersing the wind, in that they're essentially porous and flexible, compared to a solid barrier. Although a solid barrier can be used as a screen to provide shelter, that typically just diverts the wind so that it creates problems elsewhere. Alternatively, something like a tree or a hedge doesn't just divert the wind. It actually breaks up the wind and slows it down, which is the desired effect in trying to create shelter in multiple areas around the base of these buildings.

Again, these effects are something that can be assessed with physical and/or computational models. For example, by changing the materials used in a physical model in the wind tunnel, engineers can measure the impact a particular landscaping configuration will have, then substitute other materials or configurations in an iterative process to determine the best mitigation solution. Guided by the engineer's science-based approach, the architect and landscape architect can quickly see the results of successive tests and make decisions - or suggestions - turning the design into a genuine multidisciplinary, collaborative process. It's not just the engineer proposing these things; all interested parties can try their ideas for the design. Remember, too, that these choices may well now include benefits for the health and well-being of the people using the building.

\subsubsection{Commitment is required}

Of course, whenever landscaping becomes an integral part of the building plan, it requires a commitment from the building owner to maintain that landscaping. In the case of wind mitigation, for example, when a particular landscaping plan is identified as being necessary to achieve safe and comfortable conditions, then the building owner absolutely must maintain it. In some localities this is enforceable by law, but in others it is simply in the owner's best interest to do so.

\subsection{Thermal comfort}

Although wind mitigation frequently is necessary in Europe and North America, where the weather can be cold and windy, in hot climates maintaining some wind is desirable in maintaining thermal comfort. In the Middle East, for example, engineers are faced with balancing the different environmental factors to provide shade while not necessarily blocking the wind. Whereas landscaping may still be needed for some degree of wind mitigation in the Middle East, caution must be exercised to not go overboard. If the landscaping is too dense, or there is too much, it will create spaces that are totally stagnant, with no air movement whatsoever, and people will not want to be there because it will be uncomfortably hot. Palm trees are a good example of a biophilic solution that often works in this kind of application - they provide a good source of shade without blocking the wind. 
Once again, modeling can be a great help in developing an appropriate design. For projects that must strike a balance between providing shelter against high-speed winds and not blocking the airflow completely, a computational model and analysis often are selected. Such an approach makes it easier to incorporate temperature and solar effects in addition to simply assessing the wind, whereas using wind tunnel results for the wind assessment would require an additional simulation to be able to add temperature and sunlight into the design considerations.

Although designing for thermal comfort tends to not be done using such an interactive process as wind mitigation, there is no reason why it couldn't be more collaborative. In fact, computational model lends itself to this type of challenge, where there are more parameters under consideration. Testing and analyzing the computer model, discussing results with the client, deciding on some additional measures to improve the landscaping design and improve the conditions for the occupants of the space, and then running more tests to see how well the modified plans perform can ensure all parties' concerns are addressed.

More complex models can be used when there are seasonal concerns, such as how much of the year an area will receive direct sunlight. Such models can also account for the clothes people are likely to be wearing and integrate that information with seasonal changes in wind speed to predict how comfortable or uncomfortable they are likely to be.

\subsection{Air quality}

This parameter tends to be closely tied to wind. In most cases for outdoor spaces the engineer can ensure decent air quality by making sure there will be enough air movement so that air pollutants don't just stay in one place. However, this is another case that can directly conflict with wind mitigation efforts. Even though it is desirable to create a sheltered space where people are going to feel comfortable, that space cannot be so well sheltered that it has no air movement at all. In this type of analysis, computational modeling is preferred because it offers much more flexibility in introducing different pollutants into the model.

Another factor is, of course, the beneficial cleansing effect of plant life on the air. These days this is discussed primarily in terms of countering greenhouse gas concerns because trees, shrubs, and other green plants generally take in carbon dioxide $\left(\mathrm{CO}_{2}\right)$ and give off oxygen. Beyond that, trees especially provide protection from direct sunlight in the warmer months but allow more light in the colder months when their leaves have fallen.

\subsection{Noise}

For years, muffling noise was just a pleasant side-benefit of planting a hedge row, for example. However, today noise abatement is an ever-present concern, especially in urban settings, and one for which a biophilic design is often both effective and appropriate.

It's a simple case: trees and hedges can be used as a barrier to noise, and their effectiveness in that regard can be measured. Common applications include open spaces at ground level, often near a roadway, where it's a relatively easy choice. However, as for other examples previously cited, such an option must be considered along with all the other parameters involved to ensure air quality or wind mitigation measures, for example, are not being sacrificed in the process. And again, there are methods and modeling tools that engineers can use to quantify each of these parameters to assist in considering their interactions and potential trade-offs. 


\section{PRELIMINARY CONCLUSIONS}

A successful design enhances the usability of the space, creating a safe and comfortable environment that people will want to spend time in. Frequently, a biophilic approach can contribute significantly to that success by adding elements to the built environment representing the 14 categories enumerated in Section 4.

Engineering consultants must collaborate with designers to find the optimum biophilic solution that is sensitive to the other needs/uses of the area (e.g., emergency access, sight lines, visual impact, key services below street); select species that are appropriate to the climate; and balance all the conflicting environmental factors previously described.

The role of the consulting engineer also includes making sure that all potentially relevant factors can be considered. Doing so provides the owner, or developer, a scientific basis upon which to make design choices, including the measurable benefits (or other potential ramifications) of biophilic design elements. The most suitable consultants for such projects have on their team people with a variety of expertise and depth of knowledge that enables them to understand - and explain - all the available alternatives as well as the simple effect of highly complex interactions among the many choices designers ultimately must make.

\section{HIGH-RISE APPLICATIONS}

As mentioned early in this paper, building vertically is a common way to add more space for human occupation in urban areas. In turn, there is the desire to use biophilic design at higher elevations, and in many ways the challenges are similar to those found at ground level. Some significant differences do exist, however, and must be accounted for.

For instance, if trees are added to 40-story-tall balconies, or an exterior green wall is integrated with cladding, it is vital that wind loads be tested to ensure stability and safety. Although trees and greenery can reduce exposure to sun, block unwanted winds, and filter air, and thereby increase occupant well-being, they also can pose unique risks that may require creative engineering.

Building areas above ground level, such as elevated podium or terrace amenity areas, typically are more exposed to wind and sun, and typically less susceptible to noise or air quality issues because they are further away from traffic. Spaces are often smaller, and therefore offer fewer options for planting due to the restricted soil depth.

Including biophilic elements at higher elevations requires a bit more engineering. Specifically, the fact that wind speed increases with the height above the ground presents a fundamental consideration. If an outdoor open space is planned on top of a $300 \mathrm{~m}$ tall tower, it can be expected to be a rather windy environment. Here is where the engineering consultant provides vital insight into how the potential wind would interact with the design. This is done in part by measuring wind speed and in part by analyzing the structure in the context of historical weather data.

Additionally, support systems for trees, shrubs, and the like must be addressed. Especially at higher elevations there is less space than is usually available at ground level, limiting the anchorage provided by standard planting. Beyond that, the additional loads placed on the structure, such as from windblown trees, must be considered and supported.

The different way in which people use the space on elevated levels also must be taken into account. Because higher floors are frequently private space, rather than in the public realm like most ground-level space, there is more control over who gets to use the space, and when. Therefore, the mitigation of strong winds, for example, may not require the use of landscaping. It may simply mean that the building manager watches the weather forecast and locks the doors to the terrace as needed, which goes back to the benefit of a holistic design 
that considers all possible factors and opens up design options that may not have otherwise been apparent.

For high-rise applications of biophilia, the climate again informs the design and dictates how to prioritize conflicting environmental factors. A combination of hard and soft landscaping features is often optimal and frequently contributes additional benefits for building sustainability and energy use - passive cooling and natural ventilation, for example - in addition to human comfort and safety.

\section{HOW IT'S WORKING OUT}

This concluding section presents short descriptions of several recent and current projects that demonstrate biophilic design in practice.

\subsection{Bosco Verticale}

Bosco Verticale, which translates to "vertical forest", opened in Milan, Italy, in 2014. Designed by Stefano Boeri, the dual-tower project includes 780 planted trees as part of private gardens on the staggered protruding concrete balconies accompanying each unit. The taller of the two towers in this project is $112 \mathrm{~m}$ tall and includes 113 apartments. The gardens protect each unit from wind, direct sunlight, acoustic pollution, and dust particles. When Bosco Verticale was selected as the 2015 Best Tall Building Worldwide by the Council on Tall Buildings in the Urban Habitat, the jury cited the building "for its extraordinary implementation of vegetation at such scale and height. The building supplants traditional cladding materials with screens of greenery such that the plants act as an extension of the tower's exterior envelope, creating a distinct microclimate" [8].

\subsection{Viertel Zwei}

The as-yet unnamed dual-tower project designed by Mario Cucinella Architects for the Viertel Zwei district of Vienna, Austria, features two distinctly different designs. The shorter, $90 \mathrm{~m}$ tower will consist of residences and uses biophilic design to provide "a vertical extension of the existing area and of the large Prater park with the aim of establishing a relationship of continuity that is not only visual but above all qualitative between nature and built space" [9]. Various biophilic design elements have been incorporated into both towers, including floorplans and façade details that optimize natural light while at the same time minimizing glare and overheating. Plans include south-facing winter gardens for use by residents that will also enhance natural ventilation [10].

\subsection{Nanjing Green Towers}

Nanjing Green Towers, now under construction, will be the first vertical forest built in Asia. Located approximately $300 \mathrm{~km}$ up the Yangtze River from Shanghai, Nanjing is the capital of the Chinese province of Jiangsu. Designed by Stefano Boeri Architects, the Nanjing project consists of two towers, following the form of the Milan vertical forest, and is the third prototype about urban forestry and demineralization that the firm will produce worldwide. A total of 1,100 trees representing 23 local species will grace the facades, and with an additional 2,500 cascading plants and shrubs, will constitute a real vertical forest. In addition to contributing to the regeneration of local biodiversity, the forest will produce about $60 \mathrm{~kg}$ of oxygen per day while absorbing approximately 25 tons of $\mathrm{CO}_{2}$ each year [11]. As the engineering consultant on this project, RWDI used wind tunnel testing of 1:200 scale model 


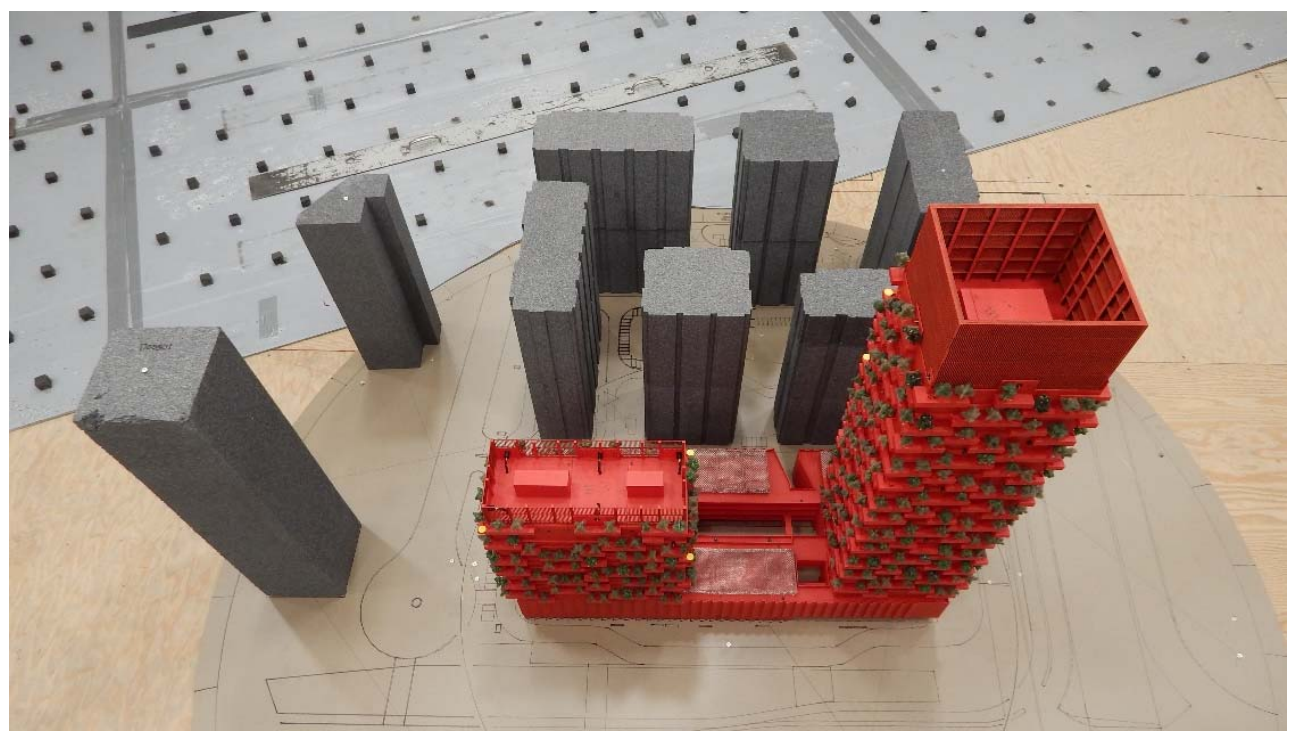

Figure 1: Scale model of Nanjing Towers with vegetation for wind tunnel testing. (Source: Courtesy of Nanjing Yang Zi State-Owned Investment Group, ARUP, and RWDI.)

prototypes, both with and without vegetation, and a wind climate assessment to perform a detailed analysis of the wind loading that must be considered to support and anchor tall and medium-sized trees at various heights above ground level.

\subsection{More case studies}

Finally, Terrapin, the New York-based sustainability consulting firm, has compiled a series of case studies demonstrating successful biophilic design. The report Biophilic Design Case Studies includes detailed descriptions of the patterns used in each project, as well as supporting images and diagrams. The report is available online at www.terrapin brightgreen.com.

\section{THE REAL CONCLUSION}

The future of building is deepening in complexity, but with biophilic design and state-of-theart engineering, the AEC community can create a utopian standard that binds modernization with the natural world for the benefit of all.

\section{REFERENCES}

[1] Sullivan, W., Kuo, F.E. \& Depooter, S., The fruit of urban nature - Vital neighborhood spaces. Environment and Behavior, 36(5), pp. 678-700, 2004. DOI: 10.1177/ 0193841 X04264945.

[2] Rogers, K., Biophilia hypothesis. In: Encyclopedia Britannica [Internet]. Encyclopædia Britannica Inc.; 2016. Online. www.britannica.com/science/biophiliahypothesis. Accessed on: 4 Jul. 2018.

[3] Urbanization of America; Active USA Center. Online. www.theusaonline.com/ people/urbanization.htm. Accessed on: 3 Jul. 2018. 
[4] Urban and Rural Areas; United Nations, Department of Economic and Social Affairs, Population Division. Online. www.un.org/en/development/desa/population/ publications/urbanization/urban-rural.shtml. Accessed on: 3 Jul. 2018.

[5] Well Building Institute website. Online. www.wellcertified.com/. Accessed on: 3 Jul. 2018.

[6] Kuo, F.E. \& Sullivan, W.C., Environment and crime in the inner city - does vegetation reduce crime? Environment and Behavior, 33(3), pp. 343-367, 2001. DOI: 10.1177/0013916501333002.

[7] Browning, W.D., Ryan, C.O. \& Clancy, J.O., 14 Patterns of Biophilic Design, Terrapin Bright Green LLC: New York, 2014. Online. www.terrapinbrightgreen.com/report/14patterns/.

[8] Bosco Verticale wins CTBUH 2015 Best Tall Building Worldwide Award. (13 Nov. 2015). CTBUH Global News. Online. www.ctbuh.org/News/GlobalTallNews/tabid/ 4810/Article/3345/language/en-US/view.aspx. Accessed on: 3 Jul. 2018.

[9] Viertel Zwei - two towers in the heart of the Vienna Prater Park. Mario Cucinella Archtitects website. Online. www.mcarchitects.it/project/viertel-zwei. Accessed on: 3 Jul. 2018.

[10] MCA Mario Cucinella Architects wins competition 'Viertel Zwei' in Vienna. (4 April 2018). Online. http://transsolar.com/news/cucinella-viertel-zwei-vienna. Accessed on: 3 Jul. 2018.

[11] Nanjing Vertical Forest. Online. www.stefanoboeriarchitetti.net/en/project/nanjingvertical-forest/. Accessed on: 3 Jul. 2018. 